\title{
LA ACTIVIDAD MILITAR COMO PROFESIÓN
}

Omar L. Gutiérrez

Para situar el debate en sus coordenadas teóricas conviene aclarar el sentido de algunos términos, en especial el significado de los vocablos profesionalización y profesionalidad. Ambos conceptos designan realidades complejas con significado dual.

La profesionalización alude al proceso histórico de la racionalización de la organización militar en su conjunto y su configuración paulatina como institución social, pero también alude al proceso de socialización de los cuadros militares y su consolidación como grupo social diferenciado.

Esta distinción operativa propuesta por Bengt Abrahamsson en "Military Professionalization and Political Power" implica, entre otras cosas, la existencia de dos planos que pueden presentar distintas condiciones de adaptación a los procesos de cambios inducidos por el entorno. La profesionalización en el sentido histórico supone la introducción de los parámetros de la eficacia y la eficiencia en la estructura de los diversos recursos de la organización militar. La socialización profesional desarrolla la cohesión del grupo social que tiene atribuido, formalmente y de facto, el control del proceso de adopción de decisiones en la estructura organizativa. A su vez, se plantea la adecuación entre los dos niveles de la profesionalización, entre la racionalización organizativa y homogeneización de valores y comportamientos producida por la socialización.

De otro lado, la profesionalidad representa, en un primer significado, la capacitación técnica adquirida durante la selección, formación, perfeccionamiento y desarrollo de la carrera militar, procesos que se llevan a cabo tanto en centros educativos específicos como en el desempeño de puestos de trabajo en distintos lugares organizativos, el otro significado se refiere a la instrumentalidad social de los cua- 
dros militares, esto es, a su subordinación al liderazgo político establecido legítimamente.

El primer aspecto supone la calificación de los militares profesionales como expertos con un monopolio de la competencia técnica en la administración de la violencia legítima. El segundo implica la protección social frente a ese monopolio, ya que los militares en tanto que funcionarios públicos, tienen que acatar la dirección politica establecida por los cauces legítimos, so pena de transgredir el orden social, desviando los fines organizativos. Resalta, pues, la posibilidad de una tensión dinámica entre ambos aspectos, pues cualquier experto con una competencia técnica delimitada ofrece resistencia a las pretensiones de control social.

¿Cuáles son las características de una profesión que distingue a un soldado profesional de otro que no lo es? En sociología, la palabra "profesión" significa algo más que "ocupación". Ser soldado como ocupación no requiere tanto poseer las características de un profesional como cumplir un importante requisito, esto es, estar relacionado continuamente con temas bélicos. Por ejemplo, los caballeros y los mercenarios han jugado un papel importante en los campos de batalla europeos, han influido en la naturaleza del quehacer bélico durante mucho tiempo; ambos grupos han contribuido a la conformación definitiva de la profesión militar; sin embargo, ambos carecen de las características, que yo considero esenciales de la profesión militar.

Pienso que una característica de la profesión militar es que el soldado posea determinados conocimientos técnicos, se le exige que tenga cierta responsabilidad para desarrollar una determinada función; el poseer conocimientos y técnicas, así como la habilidad para manipular los instrumentos necesarios, son prerrequisitos para ello. Esta competencia profesional debe permitir al soldado, no sólo cumplir con su deber, sino también cumplirlo más eficazmente que los soldados no profesionales o que los civiles. La capacidad técnica del soldado profesional deberia posibilitarle desplazar como competidores -dentro de sus propias filas-, a los no profesionales, $y$, en la medida que sean enemigos, vencerlos de forma contundente. En virtud de la competencia, el soldado profesional debería, en breve, ejercer el dominio absoluto en el campo de batalla y establecer una clara distinción entre él y los amateurs. Sin este monopolio y esta diferenciación, ninguna profesión puede configurarse ni mantenerse como tal.

Como segunda característica de la profesión militar, yo citaría el sentimiento de los miembros de la profesión de pertenecer a un grupo social distinto. Se puede imaginar, sin dificultad, que este "esprit de corps" tiene sus raices en el período de aprendizaje común en los cuarteles; esta época nutre de un sentimiento de igualdad y de ser capaces de conseguir logros que no pueden ser imitados por los no profesionales. El "esprit de corps" a su vez, levanta la barrera que rodea el grupo de profesionales, se hace cada vez más patente la idea de que si las relaciones $y$ el funcionamiento altamente cualificado son de gran importancia, la supervisión de 
la actuación profesional no debe ser dejada en manos de advenedizos. Sólo los profesionales, en virtud de su preparación, experiencia y competencia profesional, están en posición de juzgar; relegar conscientemente a los advenedizos, amplía las posibilidades de crear un estilo de vida diferenciado, incluso aparte de la excepcional posición, técnicamente determinada, que el profesional ocupa y en esta forma: el cultivo consciente de tradiciones, actitudes grupales, normas $y$ valores, que constituyen una parte de las caracteristicas de la profesión militar.

Si la primera y segunda característica de la profesión militar están relacionados entre sí, también ambas están relacionadas con la tercera. La práctica profesional sólo puede ser considerada como tal cuando aquellos que la ejercen opinan que su trabajo constituye una contribución social importante para cierta autoridad pública. En el caso del soldado profesional, el poder público es el Estado, que intenta tener el monopolio de sus servicios. Este ethos de servicio y la conciencia de participar en asuntos sociales de peso - a lo menos en la opinión de los miembros de la profesión- explica la importancia concedida a salvaguardar la competencia profesional y la supervisión interna de dicha competencia ejercidas a través de un código del honor, las cuales han sido mencionadas en la primera y segunda características; sin embargo, es propio de la profesión militar que sus miembros, al contrario de los médicos, los abogados o los procuradores, por ejemplo, ofrezcan sus servicios colectivamente, como grupo. Por otra parte, es igualmente característico que el receptor de estos servicios, en este caso el Estado, no fragmente sus demandas como en el caso de pacientes y clientes con respecto a otras profesiones.

He dejado para el final la responsabilidad social que implica una profesión; es quizás el requisito más relevante que determina el carácter profesional de su actividad. El profesional, en su condición de tal, está obligado al servicio de una sociedad y bajo esta premisa es educado; es decir, está obligado al mantenimiento de una ética profesional a lo largo de su carrera, una profesión implica una centralidad de valores, dados por la responsabilidad, cuyos principios morales orientan la actitud profesional. Se puede indicar que, debido a las demandas de la tecnología moderna, el desarrollo de los valores y comportamientos que configuran su cohesión social, el profesional de las armas dedica un tercio de su vida profesional a educación formal. Esta es la proporción más alta entre educación y tiempo de ejercicio profesional.

En consecuencia, quienes profesan la carrera de las armas son profesionales de la guerra; técnicos de las armas y del uso de la fuerza militar organizada, pero junto con ello son también hombres y ciudadanos conscientes y responsables. No habrían elegido tal profesión sin responder a una vocación, ni habría perseverado en ella si no estuviesen convencidos de que cumplen una función necesaria y útil a su patria.

Quienes hacen de su vida, profesión de servicio a la Patria - una profesión que implica riesgos, incluso el de la propia vida- están dispuestos a dar lo más pre- 
ciado de sí en defensa de los valores de Libertad, Justicia y Honor, poniendo en ello: Disciplina, Sacrificio y Valentía.

Por eso es necesario la "vocación" en un cumplimiento: La vida a bordo de los buques - por ejemplo- tanto en paz como en guerra, está marcada por muchas incomodidades sin mezcla de placer alguno. Como botón de muestra: La hora de la comida, periodo habitual de distensión para cualquier otro profesional, sigue siendo para el marino tan incómodo y poco hábil para el descanso como el resto del dia (un buque no es una plataforma fija).

Aun cuando la actividad principal de las Fuerzas Armadas es la defensa nacional, el aumento de influencia en política por militares, en el continente sudamericano, encuentra su explicación en el hecho de que los cuerpos armados han experimentado históricamente un proceso de modernización más veloz que las sociedades en las cuales se encuentran inmersos.

En los últimos años se ha producido un fenómeno singular en América Latina: diversos sistemas abiertamente militares o con gran participación de militares, han evolucionado hacia formas de poder político civil. El cambio se ha planteado sin enfrentamientos violentos, pero la situación es confusa con respecto al sector de poder que conservan las Fuerzas Armadas. Para lograr lo anterior, con regularidad se ha ido planteando la necesidad de "Redemocratizar las Fuerzas Armadas", como única alternativa de mantener el control civil, planteamiento político que también ha llegado a nuestro medio.

Después de la Segunda Guerra Mundial, en el curso de la democratización de la vida pública alemana, inspirándose en Estados Unidos, el Ejército de esa nación adoptó la teoría del "Innere Fuhrung" (Control Interior); cada oficial y soldado debía obedecer solamente aquellas órdenes que él consideraba legítimas. La propia conciencia del soldado debía juzgar hasta dónde podía llegar la disciplina, como reacción ante la "obediencia ciega" que había llevado anteriormente. La consecuencia del programa de "autodisciplina", fue el colapso de la disciplina, la caída violenta del prestigio de la carrera militar, un porcentaje muy alto de objetores de conciencia, y la agitación izquierdista, incluyendo la asociación sindical en los cuarteles. La situación comenzó a cambiar solamente después de 1970 cuando los acontecimientos demostraron que los críticos de la "obediencia ciega", en muchos casos profesores universitarios, simplemente cedían a la presión de masas de estudiantes sediciosos que los insultaban y molestaban, los obligaban a dejar sus empleos o los hacían acatar sus degradantes demandas. Si intelectuales de prestigio - profesores, decanos, periodistas-sólo atinaban a ceder ante la primera chusma vulgar que los desafiaba, no fue de extrañarse que penetraran en la cadena estructurada de mando del Ejército. Varios ejércitos han estado experimentando, con diversos grados de "democratización": disciplinas relajadas, limitación de la autoridad de los oficiales, debates institucionales ligados sobre materias políticas en las 
escuelas y cuarteles militares, abolición del saludo militar, sindicalización de sus miembros y así sucesivamente.

Estos "experimentos" han sido incorporados a la vida militar en EE.UU., Holanda, Francia, Japón y otras partes. El Almirante Elmo Zumwalt, de la Marina de los EE.UU., introdujo un concepto totalmente nuevo de disciplina relajada, que luego se extendió al Ejército y a West Point. El "Código de Honor" se debilitó cuando el ostracismo, como resultado de la conducta deshonrosa (por ejemplo, copiar en los exámenes), se "pasó de moda". Como consecuencia, el "esprit de corps" recibió un golpe decisivo, como si el propósito de los innovadores hubiese sido debilitar el eslabón individual en la cadena de la solidaridad. La vida en los cuarteles se ha vuelto más confortable con menos atención prestada a los superiores. Como contrapartida han aparecido la lucha racial, severas faltas de disciplina, y otros. Igual que los profesores hace un par de décadas, igual que los oficiales de policía desde hace algunos años, los oficiales de estos ejércitos tienden ahora a enviar informes falsos que señalan que "no hay problemas" a fin de obtener un número suficiente de "puntos favorables" para ascender o para retirarse. Como es de esperar, en todos los niveles, el eludir la responsabilidad se ha convertido en la máxima tácita; o dicho de otro modo, prevalece una actitud centrífuga sobre la actitud concentrada.

Cuando se investiga la ideologia del militar, hay que recordar lo que es una orgánica militar, que se traduce en que las decisiones tienen carácter personal y que siempre serán descendentes. Hablar de un ejército democrático es algo que no tiene sentido a la luz de las normas que lo regulan; lo que sería más correcto es referirse a ejércitos para la democracia. He tenido ocasión de comprobarlo personalmente, hay un cartel en la escuela naval de ANNAPOLIS que dice:

“La Armada está para defender la democracia de los Estados Unidos, pero la Armada no es democrática".

Es frecuente, por no decir normal, que, en los estudios que se realizan sobre los militares, se investigan los factores que los diferencian del resto de la sociedad y que se busquen en el seno de la misma institución castrense, las causas que los producen.

Ahora bien, parte del pensamiento de lo que se llama en general de "izquierda" es la búsqueda de cómo llevar a cabo una revolución intelectual-cultural, que revierta los valores morales, de manera que sin cambios externos significativos, se logre la neutralización política y una posterior desmilitarización.

El tratamiento de la temática a nivel nacional pareciera estar delimitada por las conclusiones explícitas de las Actas Finales del II Encuentro de Chantilly, Francia, 1983, en las cuales algunos participantes coinciden, en que "si bien el tema de las Fuerzas Armadas no es ajeno a las preocupaciones de la izquierda chilena, no ha recibido un tratamiento adecuado".

Los planteamientos de Chantilly señalan la necesidad del estudio del tema refe- 
rido a las instituciones castrenses. Esto incluye un análisis crítico de la "Doctrina de Seguridad Nacional" y mostrarla como un elemento inconsecuente y desnacionalizador. Otro de los acuerdos es el problema de asignar las tareas de defensa al pueblo en su conjunto, reemplazando al soldado profesional.

Finalmente, se recomienda incorporar en el discurso "de izquierda" como objetivo a perseguir: la desmilitarización.

Sabemos que para que la comunidad nacional exista y se conserve, tienen que cumplirse ciertos supuestos. Sabemos, también, que el cumplimiento de esos supuestos se garantiza mediante el desarrollo y estímulo de ciertos ideales entre sus miembros y la aplicación especializada de ellos a las acciones diarias; esos ideales se forjan en la familia, la escuela, el trabajo (también como trabajo profesional en las fuerzas armadas) y en la comunidad en general; los ideales que se transmiten de generación en generación, impulsan las conductas que mantienen con vida la comunidad nacional.

En situaciones de normalidad, una comunidad nacional, primitiva o desarrollada, produce conductas sociales que, en su inmensa mayoria, resultan positivas para la satisfacción de esos supuestos o minimos vitales. Existen, claro está, conductas desviadas, pero son absorbidas de manera formal, aislándolas y dándole un tratamiento ordinario y de rutina, sin que la comunidad se encuentre ni se sienta realmente en peligro. Se vive en paz; la mayoría de los individuos actua como estímulo y control de los demás, colaborando con las instituciones especializadas, religiosas, parentales, juridicas, militares, políticas $\vee$ de este modo, casi inconscientemente, se produce la autoconservación de la comunidad.

Finalmente, quiero dejar un pensamiento.

"A veces basta con la presencia".

Cuando se intenta demostrar, recurriendo a ejemplos clarificadores, la necesidad de Fuerzas Armadas, es frecuente utilizar el simil del bombero. Aunque haya transcurrido mucho tiempo, sin que se haya producido ningún incendio, se argumenta, es preciso mantener un cuerpo de bomberos ya que no habría posibilidad de improvisarlo cuando un edificio comience a arder. Del mismo modo, hay que mantener Fuerzas Armadas para intervenir cuando se declare una guerra.

El argumento podría considerarse válido si su propia simplicidad no lo hiciese incompleto por la sencilla razón de que la existencia del bombero no impide que se produzcan incendios, mientras que la presencia de una fuerza militar profesional puede evitar que se declare una guerra. Aunque parezca paradójico, los Estados no suelen crear Fuerzas Armadas con vista a ganar una hipotética guerra, sino con las miras puestas en evitarlas. Se trata de mantener o lograr la paz antes o después de ella. 